\title{
UCRL-JRNL-228181
}

LAW RENCE LIVERMORE N A TIO N A L LABORATORY
A Study of the Dielectric Properties of Dry and Saturated Green River Oil Shale

Jerry Sweeney, Jeffery Roberts, Philip Harben

February 20, 2007

Energy \& Fuels 
This document was prepared as an account of work sponsored by an agency of the United States Government. Neither the United States Government nor the University of California nor any of their employees, makes any warranty, express or implied, or assumes any legal liability or responsibility for the accuracy, completeness, or usefulness of any information, apparatus, product, or process disclosed, or represents that its use would not infringe privately owned rights. Reference herein to any specific commercial product, process, or service by trade name, trademark, manufacturer, or otherwise, does not necessarily constitute or imply its endorsement, recommendation, or favoring by the United States Government or the University of California. The views and opinions of authors expressed herein do not necessarily state or reflect those of the United States Government or the University of California, and shall not be used for advertising or product endorsement purposes. 


\title{
For submittal to Energy and Fuels
}

\section{A Study of the Dielectric Properties of Dry and Saturated Green River Oil Shale}

\author{
Jerry J. Sweeney, Jeffery J. Roberts, Philip E. Harben \\ Lawrence Livermore National Laboratory, P.O. Box 808, Livermore, CA 94550
}

\begin{abstract}
We measured dielectric permittivity of dry and fluid-saturated Green River oil shale samples over a frequency range of $1 \mathrm{MHz}$ to $1.8 \mathrm{GHz}$. Dry sample measurements were carried out between room temperature and $146{ }^{\circ} \mathrm{C}$, saturated sample measurements were carried out at room temperature. Samples obtained from the Green River formation of Wyoming and from the Anvil Points Mine in Colorado were cored both parallel and perpendicular to layering. The samples, which all had organic richness in the range of 10$45 \mathrm{gal} / \mathrm{ton}$, showed small variations between samples and a relatively small level of anisotropy of the dielectric properties when dry. The real and imaginary part of the relative dielectric permittivity of dry rock was nearly constant over the frequency range observed, with low values for the imaginary part (loss factor). Saturation with de-ionized water and brine greatly increased the values of the real and imaginary parts of the relative permittivity, especially at the lower frequencies. Temperature effects were relatively small, with initial increases in permittivity to about $60^{\circ} \mathrm{C}$, followed by slight decreases in permittivity that diminished as temperature increased. Implications of these observations for the in situ electromagnetic, or radio frequency (RF) heating of oil shale to produce oil and gas are discussed.
\end{abstract}

\section{INTRODUCTION}

In a relatively small area of the western United States, nearly $60 \%$ of the world's oil shale resource base resides, about 1.5 trillion potential barrels of oil. This is 1.5 times larger than estimates of current worldwide proven petroleum reserves. Increasing prices for crude oil have prompted a fresh look at the potential for in situ conversion of these oil shale reserves into a petroleum product that can be conventionally pumped with acceptable environmental impact. Primary challenges for in situ conversion of oil shale to recoverable petroleum are determining the most effective and economical means to (a) heat the formation to temperature where kerogen is converted, (b) extract the converted oil, and (c) minimize contamination of local fluids by the process. In this paper we address questions related to the first of these considerations.

One approach to oil shale in situ formational heating that is being considered is radio frequency (RF) dielectric heating at slow rates compared to retorting (Burnham, 2003). RF heating is worthy of study because it can be applied in situ with significant environmental advantages and, if feasible, can provide improvements in heating 
efficiency and process control that other methods such as direct current heating, inductive heating, or steam injection cannot provide. Several companies have patented in-situ oil shale heating technologies ultimately dependent on conductive heating, which suggests a rejection of the RF heating approach, but we have found no published reports that give conclusive evidence for accepting or rejecting slow-deposition-rate RF dielectric heating. With slower heating rates, oil will evolve at lower temperatures but will take longer to accomplish (Burnham, 2003). One difficulty in assessing the potential of RF heating technology is that the fundamental dielectric properties of oil shale at conditions approximating in situ are not understood. Questions about process control, formational behavior as heating progresses, oil recovery, etc. are all secondary to one fundamental question: Can RF energy penetrate the rock formation and effectively heat kerogen in a larger region about the heating source than diffusive methods at lower energy cost? This depends on how dielectric loss of oil shale behaves as a function of frequency, water saturation, temperature, pressure, and kerogen content. This paper is a report of an experimental study on well-characterized samples under controlled conditions in order to answer some of the questions needed to assess the feasibility of in-situ RF heating as a viable process for oil shale exploitation.

Our study is based on shale samples obtained from the Green River Shale formation of southern Wyoming and northwestern Colorado. One set of samples, provided by Anadarko Petroleum Company, come from the Green River Basin of southwest Wyoming, and will be here referred to as Anadarko shale. The other set was obtained from the U.S. Bureau of Land Management Anvil Points mine near Glenwood Springs, Colorado, and will be referred to as Anvil Points shale. Core samples were cut, both parallel and perpendicular to the shale bedding planes, from the original pieces of rock provided and samples were prepared suitable for dielectric measurements. We carried out measurements of dielectric permittivity on dry and wet (de-ionized water and brine) samples with different levels of saturation at room temperature and on dry samples at temperatures up to $146^{\circ} \mathrm{C}$. In this paper we provide a summary of the results of these measurements and provide our interpretation of these results in terms of possible application of radio frequency heating to in situ recovery of petroleum from oil shale.

\section{DIELECTRIC PROPERTIES AND ANALYSIS}

We follow the following conventions established by Von Hippel (1954) for the study of dielectric properties. The dielectric constant of a material is defined as

$$
\varepsilon^{*}=\varepsilon^{\prime}-j \varepsilon^{\prime \prime}
$$

where $j$ is $\sqrt{-1}$ and $\varepsilon^{\prime}$ and $\varepsilon^{\prime \prime}$ are the real and imaginary parts of the dielectric constant. The relative dielectric constant is defined as

$$
k^{*}=\frac{\varepsilon^{\prime}}{\varepsilon_{0}}=k^{\prime}-j k^{\prime \prime}
$$


where $\varepsilon_{0}$ is the permittivity of free space, $8.854 \times 10^{-12} \mathrm{~F} / \mathrm{m}$. Dielectric parameters are usually determined from impedance measurements using capacitor circuits.

Another parameter commonly used is the loss tangent, which is defined as the ratio of the loss current to the charging current in the electrical circuit. In terms of the dielectric parameters, loss tangent is defined (Von Hippel, 1954) as

$$
\tan \delta=\frac{\varepsilon^{\prime}}{\varepsilon^{\prime \prime}}=\frac{k^{\prime}}{k^{\prime \prime}}
$$

The dielectric conductivity is a function of angular frequency, $(\omega=2 \pi f$, where $\mathrm{f}$ is frequency in $\mathrm{Hz}$ ):

$$
\sigma=\omega \varepsilon^{\prime \prime}\left[\mathrm{ohm}^{-1} \mathrm{~m}^{-1}\right]
$$

From these parameters, we define power absorbed per unit volume as

$$
P=\frac{\sigma E^{2}}{2}=\frac{\omega \varepsilon^{\prime \prime} E^{2}}{2}\left[\mathrm{watt} / \mathrm{m}^{3}\right]
$$

Where $\mathrm{E}$ is the magnitude of the electric field strength in the material. For material with negligible magnetic loss, the rate of decay of the electric field as it travels through a material (the attenuation factor, $\alpha$ ) is defined by

$$
\alpha=\frac{2 \pi}{\lambda_{0}}\left[\frac{1}{2} k^{\prime}(\sqrt{1+\tan 2 \delta})-1\right] \quad \text {. }
$$

For small values of $\tan \delta, \sqrt{1+\tan ^{2} \delta}-1 \approx \frac{\tan ^{2} \delta}{2}$ and the attenuation becomes

$$
\frac{\pi}{\lambda_{o}}\left[\left(k^{\prime}\right)^{1 / 2} \tan \delta\right]
$$

Here, $\lambda_{0}$ is the free-space wavelength. The inverse of the attenuation constant, $\frac{1}{\alpha}$, is referred to as the skin depth, which is the distance within the material where the field strength is decreased by $\frac{1}{e}$. The ability to heat a material with radio frequency energy depends on the dielectric loss and on the thermal capacity of the material, $\rho C_{p}$, where $\rho$ is the material density and $C_{p}$ is heat capacity, which is typically on the order of about 2 $\mathrm{X} 10^{6} \mathrm{~W}$-s $\mathrm{m}^{-1}{ }^{\circ} \mathrm{K}^{-1}$ for rock. To heat a volume of material at a rate of $\frac{\Delta T}{t}$, where $\mathrm{t}$ is time and $\Delta \mathrm{T}$ is temperature change, we use (5) to obtain 


$$
\frac{\Delta T}{t}=\frac{\omega \varepsilon_{0} k^{\prime} \tan \delta|E|^{2}}{\rho C_{p}} .
$$

For a given heating rate, we can use (6) to find the electric field strength needed to heat the material as a function of the frequency, relative dielectric constant, and loss tangent:

$$
|E|^{2}=\frac{\rho C_{p}\left[\frac{\Delta T}{t}\right]}{\omega \varepsilon_{0} k^{\prime} \tan \delta} .
$$

The denominator of (9) is often referred to as the power dissipation factor.

Materials that contain polar molecules, such as water, display a relaxation phenomenon at high radio frequencies due to the fact that rotation of the molecule can't keep up with the applied field. A form of the Debye equation illustrating this (Gabriel et al., 1998) is

$$
k^{\prime}-k_{\infty}^{\prime}=\frac{k_{s}^{\prime}-k_{\infty}^{\prime}}{1+\omega^{2} \tau^{2}} \quad k^{\prime \prime}=\frac{\left(k_{s}^{\prime}-k_{\infty}^{\prime}\right) \omega \tau}{1+\omega^{2} \tau^{2}}
$$

where $k_{s}^{\prime}$ is $k^{\prime}$ at the low frequency limit, $k_{\infty}^{\prime}$ is $k^{\prime}$ at the high frequency limit, and $\tau$ is the relaxation time of the molecule. For pure water, $k^{\prime}$ is a constant with a value of about 80 $\left(k_{s}^{\prime}\right)$ for frequencies below the GHz range, $k^{\prime}$ begins to decrease at about $1 \mathrm{GHz}$ and reaches $k_{\infty}^{\prime}$ at frequencies $>10^{11} \mathrm{~Hz}$. The value of $k^{\prime \prime}$ is essentially zero and rapidly increases to a peak at a frequency of about $10 \mathrm{GHz}$ and then decreases. The loss peak occurs at a resonant frequency related to the molecule relaxation time. Such relaxation for water is exploited in microwave heating in commercially available home ovens. Organic solvents and other polar organic materials often display dielectric relaxation phenomena over a wide range of frequencies (Gabriel et al., 1998). One question we wanted to answer in this study is whether the organic matter (kerogen) contained in oil shale, or some of its constituents, might demonstrate dielectric relaxation at some temperature or frequency that we would be able to impose on the shale.

\section{PREVIOUS STUDIES OF THE DIELECTRIC PROPERTIES OF OIL SHALE}

A review of the literature for reports of dielectric measurements on oil samples reveals fundamental information about how dielectric properties are affected by the frequency of measurement, temperature, and oil yield of the shale for dry rock. Moisture content has a strong effect on dielectric properties (Piwinskii and Duba, 1976) and Nottenburg et al. (1979) showed that values of dielectric parameters decreased with successive drying cycles of the shale samples. As with all porous materials, presence of water in the pore space will have a large effect on dielectric properties because the real part of the relative dielectric constant of liquid water is very high $(\sim 80)$ compared to that of the matrix (typically less than 10 at high frequencies), and because of the polar nature of the water molecule. Addition of ions to the water adds to its conductivity and, at frequencies below a few MHz, significantly increases dielectric constant and loss factor because of low 
frequency ionic effects. Other than the study of Nottenburg et al. (1979), we have found no studies of the effect of pore water on the dielectric properties of oil shale; this is probably due to the difficulty of quantifying the level of saturation of very low porosity rock as well as the very high conductivities and dielectric constants of saturated rock at low frequencies.

In an analysis of the contributions of rock matrix constituents to the dielectric properties of shale, Rajeshwar and Inguva (1985) point out that air and kerogen $\left(k^{\prime} \approx 1.0\right.$ and 2.3, respectively) are contributors for low values of permittivity, while water, pyrite, and ferric oxide ( $k^{\prime} \approx 80.0,33.7$, and 25.0 , respectively) are contributors to high values of permittivity. This is verified by the findings of Duba and Piwinskii (1976), Nottenburg et al. (1979), Laine and Lytle (1980), Rajeshwar et al. (1980) and Jesch and McLaughlin (1984) who all observed lower values of the real part of the relative dielectric permittivity for shale samples with higher oil yield (e.g. as the amount of organic matter in the rock increased). All the above studies on dry oil shale also show a decrease in the values of dielectric properties with higher frequencies (see Table 1). The only study carried out in mid-range radio frequencies was that of Rajeshwar et al. (1980, $10-1000 \mathrm{MHz}$ ); other studies were at single or lower frequencies or much higher (Briggs et al., 1983; 8-12 $\mathrm{GHz})$.

Two studies (Hu, 1979 and Jesch and McLaughlin, 1984) looked at the effect on dielectric properties of heating shale through the point where organic matter was released by pyrolysis. The report by Hu (1979) was not quantitative, but $1000 \mathrm{~W}$ of microwave power at $915 \mathrm{MHz}$ was used to heat a sample at $287^{\circ} \mathrm{C} / \mathrm{min}$. A rapid change in dielectric properties occurred starting at $450^{\circ} \mathrm{C}$. Jesch and McLaughlin (1984) observed a rapid increase in dielectric properties between $400^{\circ}$ and $500^{\circ} \mathrm{C}$ accompanied by oil evolution from the sample. The study by Briggs et al. (1983) took samples up to $250^{\circ} \mathrm{C}$ with little change in dielectric properties noted. Rajeshwar and Inguva (1985) suggest that as temperatures reach the point where the polar molecules in the organic fraction start to mobilize, the dielectric properties will probably begin to increase, but quantitative data is not supplied. Clearly the kerogen in the shale is non-polar and has a low values of dielectric permittivity and loss at frequencies greater than $10 \mathrm{MHz}$ or so until temperatures reach the point where it begins to break down into gas and oil, which are heating rate dependent [see Burnham and Singleton (1983) for discussion of pyrolysis kinetics of Green River oil shale]. Table 1 summarizes the general quantitative observations discussed above from some of the references. 
Table 1. Summary of dielectric properties of oil shale at different frequencies.

\begin{tabular}{|l|l|l|l|l|}
\hline Frequency & $\begin{array}{l}\text { Real part } \\
\text { relative } \\
\text { dielectric } \\
\text { permittivity }\end{array}$ & $\begin{array}{l}\text { Imaginary part } \\
\text { relative } \\
\text { dielectric } \\
\text { permittivity }\end{array}$ & Loss tangent & Conductivity \\
\hline $50-100 \mathrm{~Hz}^{1}$ & $16-150$ & 5 & & \\
\hline $1 \mathrm{MHz}^{2}$ & 10 & 1 & & \\
\hline $10 \mathrm{MHz}^{3}$ & 10 & 1 & & $3.3-14 \mu \mathrm{S} / \mathrm{m}$ \\
\hline $45 \mathrm{MHz}^{4}$ & $4-8$ & & $0-0.1$ & \\
\hline $200 \mathrm{MHz}^{5}$ & $4-6$ & $0.2-0.6$ & $0-6$ & \\
\hline
\end{tabular}

Our conclusions, based on the above survey of past studies, are as follows: (1) there are relatively few studies of oil shale dielectric properties in the $10 \mathrm{MHz}-1 \mathrm{GHz}$ range; (2) the effect of partial saturation with pure water or brine on dielectric properties is not well characterized; and (3) it is not known if any dielectric relaxation mechanisms exist for oil shale in the $10 \mathrm{MHz}-1 \mathrm{GHz}$ range. Finally, for application of radio frequency heating to in situ pyrolysis of oil shale, we would like to understand the implications of the effects that pure water and brine content in low porosity rock have on critical parameters for heating, such as skin depth. The intent of our measurement campaign was to study the dielectric behavior of dry, partially saturated, and saturated oil shale with different organic content over temperature ranges from room temperature to those as high as possible with the measurement apparatus available and over a frequency range likely to be applicable to in situ conditions (10 MHz - $1 \mathrm{GHz})$.

\section{SAMPLE DESCRIPTION AND MEASUREMENT SYSTEM}

Oil shale samples from the Green River Formation of southwestern Wyoming were provided by Anadarko Petroleum Company, and samples from the Anvil Points Mine in Colorado were provided by the U.S. Bureau of Mines. Pieces of rock about $10-15 \mathrm{~cm}$ in size were collected from either fresh core (Anadarko) or in-mine outcrop (Anvil Points) and shipped to our laboratory. These rock samples were relatively fresh and dry, but were not given any special protective treatment prior to sample preparation. Cores $2.54 \mathrm{~cm}$ diameter were cut both perpendicular and parallel to shale layering (bedding planes). Small disks $5 \pm 0.1 \mathrm{~mm}$ thick were cut from the core samples. After labeling, the samples

\footnotetext{
${ }^{1}$ Piwinskii and Duba (1976) and Nottenburg et al. (1979)

2 Nottenburg et al. (1979)

${ }^{3}$ Jesch and McLaughlin (1984)

${ }^{4}$ Laine and Lytle (1980) done in situ, cross-well measurements in dry rock

${ }^{5}$ Rajeshwar et al. (1980) and Briggs et al. (1983)
} 
were placed in a vacuum oven at $35^{\circ} \mathrm{C}$ for drying. After at least several days in the oven the shape and weight of the samples were measured to determine dry density. From the dry density, we used the relationship of Smith (1969) to compute the organic richness of the Anvil Points samples. Measured dry densities for Anvil Points samples were $1.947 \pm 0.57 \mathrm{~g} / \mathrm{cm}^{3}$, with calculated richness $45.28 \pm 4.83 \mathrm{gal} / \mathrm{ton}$. Chemical analyses of the Anadarko samples revealed organic carbon content (weight percent) ranging from 4.7 to 11.0, which is equivalent to an organic richness ranging from 9.8 to 24.3 gal/ton, using the relationship given by Singleton (1986).

It is very difficult to measure exactly and control saturation in very low porosity rock samples such as oil shale. Our approach was to initially dry the samples until weight loss stabilized, indicating that there was little to no pore fluid left to lose. After completing a set of measurements on dry samples, a subset were placed in a nitrogen gas environment, evacuated, and backfilled with either de-ionized water or brine pressurized to 45 psi. Sample were weighed and then left in the solution until the weight stabilized, typically in about 7-8 days. Porosity was estimated by subtracting dry density from wet density. Saturation levels of the sample could then be determined by comparing current sample weight with the dry and fully saturated weight. This was done on samples in both orientations with respect to the shale layering.

When a sample has been saturated with brine and later dried, a salt residue can be left behind in the pore space which can alter the electrical properties of the dry shale. In addition, the small wafers of oil shale that we performed measurements on are very delicate, especially during or after being heated to $100{ }^{\circ} \mathrm{C}$ or higher. For this reason, we left the higher temperature measurements to be completed last on samples that had never been saturated. Because of limitations of our ability to calibrate the measurement system at high temperatures we did not extend sample temperatures beyond $150{ }^{\circ} \mathrm{C}$.

The measurement system for the dielectric measurements consisted of a Hewlett-Packard 4291A Radio Frequency Impedance/Material Analyzer connected to an Agilent 85070E dielectric probe kit with a high temperature probe. The analyzer operates over a frequency range of $1 \mathrm{MHz}$ to $1.8 \mathrm{GHz}$. The system is connected to a PC that collects, stores, and displays data from each sample run. For each sample run 801 data points were collected between $1 \mathrm{MHz}$ and $1.8 \mathrm{GHz}$. After the standard calibration procedure using a short, open circuit, and load impedance, we ran measurements on Teflon samples to verify that there were no major problems with the calibration over the entire frequency range. Typical calibrated results for a series of these runs on Teflon is shown is Figs. 1 and 2. As Figs. 1-2 show, calibration begins to show large errors below $10 \mathrm{MHz}$ and above $1 \mathrm{GHz}$; these are probably due to limitations of the Agilent sample holder assembly. Nominal values of the real part of relative dielectric constant of Teflon are 2.05 -2.1 and the imaginary part is close to zero. Once the system is calibrated and running, it only takes 2-3 minutes to complete a measurement on a sample. Note also that the system measures impedance and can thus provide output parameters in whatever equivalent format that is desired. For each measurement, we recorded the following equivalent parameters: impedance magnitude $(|\mathrm{Z}|)$ and phase $(\phi)$, loss factor $\left(k^{\prime \prime}\right)$ and loss tangent $(\tan \delta)$, real part of the relative dielectric constant $\left(k^{\prime}\right)$ and loss tangent $(\tan \delta)$, and $k^{\prime}$ and 
$k^{\prime \prime}$ (real and imaginary parts of the relative dielectric constant). Results we show here will be in terms of the real and imaginary parts of the relative dielectric constant ( $k^{\prime}$ and $k^{\prime \prime}$ ) over the frequency range of $8 \mathrm{MHz}$ to $1 \mathrm{GHz}$.

Because the face of a shale sample disk is much larger in area than the area of the sample probe, we also investigated the uniformity of the samples in both of the sample core orientations. Variations across the sample are too small to introduce measurement differences due to sample thickness alone. Using a registration mark on the sample as reference, we rotated the sample in the plane of the disk to make 8 equally spaced measurements. As discussed below, these successive measurements only showed significant differences for saturated samples, when moisture would slowly evaporate from the sample as it was rotated for successive measurements.

\section{MEASUREMENT RESULTS}

As mentioned above, one of the first things we wanted to investigate was variability of the relative permittivity due to the position of the sample within the sample holder. Figs. 3 and 4 show real and imaginary parts of the relative permittivity from $8 \mathrm{MHz}$ to $1 \mathrm{GHz}$ as a function of position of the sample in the sample holder as described in the paragraph above. These are for a dry sample of Anvil Points shale cored perpendicular to the layering and are typical of all the shale samples. The variation of the real part is on the order of 1-2\%; variation for the imaginary part is much smaller. The anomaly in the measurements occurring near $100 \mathrm{MHz}$ is a systematic error related to the instrument calibration; in general the real part is constant with frequency, with a very slight decrease at the highest frequencies. The loss factor (imaginary part) is very small $(<0.02-0.03)$ over the frequency range with a small decrease at the highest frequencies. As was the case for the Teflon standard (see above), noise levels are highest below about $20 \mathrm{MHz}$ and above $200 \mathrm{MHz}$. Similar measurements on both Anadarko and Anvil Points samples in the transverse direction (parallel to the layering) showed more variation with sample position, probably because of subtle variations as the relative position of the layering changes with rotation. Finally, there is no evidence over the frequency range shown in Figs. 3 and 4 of any relaxation mechanism.

Because we prepared samples from different rock specimens, we were able to look at inter-sample variability, as shown in Figs. 5 and 6. These figures show the real and imaginary part of the relative permittivity for four different pieces of dry Anadarko shale. First note that both the real and imaginary part of the relative permittivity are higher for the Anadarko samples compared to the Anvil Points sample. The real part of the permittivity varies about $10 \%$ between samples with a slightly larger variability for the imaginary part. The vertical scale for these figures is larger, making the noise levels appear to be smaller, although the anomaly at $100 \mathrm{MHz}$ does not appear in these data. Differences in relative permittivity between samples does not in this case appear to be related to organic richness; sample OS4 has the largest organic richness (24.3 gal/ton) among these samples while sample OS6 has the lowest (9.8 gal/ton). Samples OS5 and OS7 have very similar values of organic richness (16.9 and $16.0 \mathrm{gal} / \mathrm{ton})$. 
Figures 7 and 8 show the effect of saturation with de-ionized water on the relative permittivity of Anvil Points shale. The curves for dry rock, $0 \%$ saturation, are the same as those shown in Figs. 3 and 4 (note the scale difference). The real and imaginary part of the relative permittivity are at their lowest values and relatively unvarying with frequency. As the saturation level increases, both the real and imaginary parts of the permittivity increase, especially at the lower frequencies, where ionic conduction effects dominate. This effect is not expected for pure water and indicates that, during saturation, salts left behind in the pore space are mobilized and rock dissolution occurs. This is verified by an observed increase in conductivity of the bulk fluid after the dry rock sample was placed in the beaker of de-ionized water.

Samples saturated with brine show behavior similar to those saturated with de-ionized water - increased values of the real and imaginary parts of the permittivity over all frequencies but especially at high frequencies - but the effect is much larger, presumably due to the higher ionic content of the fluid. The brines we used to saturate our samples were relatively low conductivity $(658 \mu \mathrm{S} / \mathrm{cm})$ and chosen to be the same as the mean value of those observed at shallow depths in natural ground water where the Green River shale occurs (Apodaca, 1998).

Effects of temperature on relative permittivity are shown in Figs. 9-12 for Anvil Points shale. Figures 9 and 10 show the progressive changes in the real and imaginary part of the relative permittivity as temperature changes from $23{ }^{\circ} \mathrm{C}$ to $100{ }^{\circ} \mathrm{C}$. These are samples cut so the measurement is in the direction parallel to layering. Initially, the real and imaginary parts increase with temperature, up to $65^{\circ} \mathrm{C}$, then they decrease. At $100{ }^{\circ} \mathrm{C}$ both the real and imaginary parts have decreased to values below those at room temperature. This may indicate additional drying of the samples or removal of humidity effects from the ambient atmosphere. Effects of temperature are greatest at the lower frequencies. However, these temperature effects are not dramatic; differences are on the order of about $15 \%$. It is unlikely that any changes in chemical or material properties are occurring. Figures 11 and 12 show changes in real and imaginary part of the relative permittivity for an Anvil Points shale sample cut perpendicular to layering for temperatures up to $146^{\circ} \mathrm{C}$, the highest temperature we were able to safely and reliably obtain with our measurement system. As the figures show, changes with temperature are very small in this range, and it is obvious that calibration compensation of the measurement system begins to fail above about $200 \mathrm{MHz}$ for the highest temperatures.

The data shown so far illustrate the following: both the real and imaginary parts of the relative dielectric permittivity of the Anadarko and Anvil Points shale are nearly the same and show relatively small changes with frequency over the range $8 \mathrm{MHz}-1 \mathrm{GHz}$ for dry samples. Samples saturated with de-ionized water show significant increases in permittivity at the lower frequencies with even larger increases occurring when the conductivity of the fluid is increased. Temperature has a relatively minor effect on dielectric properties of dry shale for temperatures well above $100{ }^{\circ} \mathrm{C}$. The next questions to address are related to the ultimate application of in situ conversion of oil shale to petroleum - how the permittivity parameters relate to the penetration of radio frequency energy and its ability to heat the formation. 
The ability to efficiently produce radio frequency energy and deliver it to specific areas of the formation of interest (i.e., where the richest kerogen is located) is a complicated subject that involves power conversion and antenna design and matching to the variable characteristics of the underground material. For these reasons, we avoid trying to discuss the magnitude of the electric field required to deliver power to the formation for particular heating rates. A more tractable approach is to estimate the relative ability of the radio frequency energy to penetrate the medium by calculating the skin depth, using the inverse of (7). Note, however, that the skin depth, $\frac{1}{\alpha}$, involves division by $\tan \delta$, which can be a very small number with significant noise. This results in considerable noise in the calculated values. For the figures discussed below, we compensate for this considerable noise effect by applying a smoothing algorithm to the plotted curves.

Figure 13 shows skin depth versus frequency calculated for the four dry Anadarko shale samples of Figs. 5 and 6. The figures show that skin depth is 100s of meters at frequencies around $10 \mathrm{MHz}$, but decreases to $50 \mathrm{~m}$ or less at $100 \mathrm{MHz}$. These results are mimicked by the Anadarko shale samples, shown in Fig. 14. Saturation with water significantly alters the skin depth, as shown in Fig. 15 for the Anadarko samples and Fig. 16 for the Anvil Points shale samples saturated with de-ionized water. This is probably the minimum effect to be expected for a saturated sample, yet the difference in skin depth between the saturated and dry samples is significant. Figure 16 shows a more realistic difference in skin depth, for brine-saturated samples, which show that skin depth is typically less than $10 \mathrm{~m}$ for frequencies greater than $10 \mathrm{MHz}$.

\section{CONCLUSIONS AND IMPLICATIONS}

Data obtained in this study make it clear that fluid content has a huge effect on the dielectric properties of oil shale. Oil shale that is fully or partially saturated with water will exhibit much higher loss factor and much smaller skin depth than dry rock. For temperatures up to about $150{ }^{\circ} \mathrm{C}$, this study shows that there is a relatively small effect of temperature on dielectric properties. However, the work of Jesch and McLaughlin (1984) showed that at temperatures where kerogen starts to decompose the dielectric properties will begin to change significantly. The temperature at which kerogen begins to decompose is driven by chemical kinetics and thus will depend on heating rate (Burnham and Singleton, 1983). Higher heating rates will lead to kerogen breakdown at higher temperatures, but lower heating rates will lead to kerogen breakdown at lower temperatures (Burnham, 2003) and may actually produce oil with a composition closer to that of naturally produced oil.

The conundrum for radio frequency in situ heating of oil shale is as follows. At most depths of interest, in situ oil shale will be below the water table and saturated with conductive fluid. Our study shows that in this saturated condition the shale will have a high loss factor and a low value of skin depth. Regardless of the means of applying the radio frequency energy, this means that for saturated rock, energy will not penetrate deeply into the formation and most of the heating effect will occur near the energy 
source. This is a common problem, even for conductive heating methods. As long as the temperature of the formation is below the boiling point and the rock is still moist, the fluid will dominate the heating process. This will be true for almost any conceivable geologic setting composed of sedimentary rock, since sandstone, siltstone, and limestone all will have dielectric properties dominated by the fluid in the pore space. However, once the formation begins to dry out, the radio frequency heating environment will change drastically. For dry rock, the loss factor is very low, and skin depth increases from 10 s of meters to 100s of meters. Radio frequency energy is able to penetrate deep into the formation. The conundrum is that the reason it can penetrate is because loss is low and thus less power is absorbed by the rock and the effectiveness of radio frequency heating is drastically reduced. Once the oil shale has been somehow heated to temperatures at which the organic matter begins to decompose, then the dielectric loss in the kerogen will begin to change rapidly and a dynamic process will begin in which radio frequency heating may be very effective for efficiently converting the kerogen to oil and gas under changing conditions by adjusting the applied frequency.

The challenge for radio frequency in situ oil conversion of oil shale is how to deal with the drastically different saturated and unsaturated conditions. More complicated strategies that alternate between heating methods based on variable conditions my speed up heating and reduce energy input; for instance, an early phase of diffusive (conductive) heating or pumping may be preferable for removing fluids from the formation. As drying of the formation occurs, the radio frequency energy will penetrate deeper, and perhaps make this method more effective for heating at this stage than diffusive methods.

Once kerogen breakdown begins, the loss factor will increase in the organic matter. This will cause radio frequency energy to concentrate into this part of formation and make this heating method particularly effective at this stage. The complex nature of the dynamic processes involved in all the stages of heating oil shale in situ under natural conditions is difficult to model with confidence. Resolution of the many questions related to the process will most likely come about by means of carefully monitored pilot-scale experiments in the field.

\section{ACKNOWLEDGEMENTS}

We express special thanks to Steve Carlson and Bill Ralph for excellent assistance with the laboratory measurements. Hansel Neurath wrote codes to collect the HP data and convert it into PC files. Anadarko Petroleum Company and the U. S. Bureau of Mines provided oil shale rock samples. The project was funded through support of the LDRD program at LLNL. This work was performed under the auspices of the U.S. Department of Energy by the University of California, Lawrence Livermore National Laboratory under Contract W-7405-Eng-48. 


\section{REFERENCES}

Apodaca, L. E., 1998, Analysis of Ground-Water-Quality Data of the Upper Colorado River Basin, Water Years 1972-92, U. S. Geological Survey Water-Resources Investigations Report 97-4240, p. 11.

Briggs, W. E., J. E. Lewis, and J. M. Tranquilla, 1983, Dielectric Properties of New Brunswick Oil Shale, Journal of Microwave Power, 18 (1), 75-82.

Burnham, A. K., 2003, Slow Radio-Frequency Processing of Large Oil Shale Volumes to Produce Petroleum-like Shale Oil, Lawrence Livermore National Laboratory Report UCRL-ID-155045.

Burnham, A. K. and M. F. Singleton, 1983, High-Pressure Pyrolysis of Green River Oil Shale, in ACS Symposium Series 230, F.P. Miknis and J. F. McKay, eds., American Chemical Society, Washington D. C., pp. 335-351.

Gabriel, C., S. Gabriel, E. H. Grant, B.S.J. Halstead, and D. M. P. Mingos, 1998, Dielectric parameters relevant to microwave dielectric heating, Chemical Society Reviews, v. 27, pp. 213-223.

Hu, Chia-Lun J., 1979, Online Measurements of the Fast Changing Dielectric Constant in Oil Shale Due to High-Power Microwave Heating, IEEE Trans. Microwave Theory and Techniques, v. MTT-27, no. 1, January, 6 pp.

Jesch, R. and R. H. McLaughlin, 1984, Dielectric Measurements of Oil Shale as Functions of Temperature and Frequency, IEEE Trans. Geosci. Remote Sensing, vol. GE22, no. 2, 99-104.

Laine, E. F., and R. J. Lytle, 1980, In Situ Measurements of High Frequency Electrical Conductivity and Permittivity of Oil Shale, LLNL report UCRL-84306, 8 pp.

Nottenburg, R., K. Rajeshwar, M. Freeman, and J. Dubow, 1979, Thermochimica Acta, 31, pp. 39-46.

Piwinskii, A. J., and A. Duba, 1976, The Permittivity and Electrical Conductivity of Oil Shale, Int. J. Rock Mech. Min. Sci. \& Geomech. Abstr. Vol. 13, pp. 165-166.

Rajeshwar, K., and R. Inguva, 1985, Application of dielectric spectroscopy to chemical characterization of oil shales, Fuel, v. 64, 931-937.

Rajeshwar, K., J. DuBow, and R. Thapar, 1980, Radio-frequency electrical properties of Green River oil shales, Can. J. Earth Sci., vol. 17, pp. 1315 -1321.

Singleton, M. F., 1986, Assay Products from Green River Oil Shale, Lawrence Livermore National Laboratory Report UCRL-53273 rev. 1, 207 pp. 
Smith, J., 1969, Theoretical Relationship Between Density and Oil Yield for Oil Shales, U. S. Bureau of Mines Publication no. 7248.

Snow, R. H., J. E. Bridges, S. K. Goyal, and A. Taflove, 1979, Comparison of Dielectric Heating and Pyrolysis of Eastern and Western Oil Shales, In Situ, 3 (3) 255-256.

Von Hippel, A. R., 1954, Dielectrics and Waves, John Wiley and Sons, New York, pp. 26-28.

\section{FIGURE CAPTIONS}

Figure 1. Real part of relative dielectric permittivity measured on a Teflon sample, plotted versus applied frequency. Five separate measurements, with instrument compensation, are shown.

Figure 2. Imaginary part of relative dielectric permittivity measured on a Teflon sample, plotted versus applied frequency. Five separate measurements, with instrument compensation, are shown.

Figure 3. Real part of relative dielectric permittivity plotted versus frequency for a dry Anvil Points shale sample. This sample was cored in the direction perpendicular to layering. Eight separate measurements, made at different points in single sample, are shown.

Figure 4. Imaginary part of relative dielectric permittivity plotted versus frequency for a dry Anvil Points shale sample. This sample was cored in the direction perpendicular to layering. Eight separate measurements, made at different points in single sample, are shown.

Figure 5. Real part of the relative dielectric permittivity plotted versus frequency for four different Anadarko shale samples. Samples are dry and at room temperature and each has a slightly different organic content.

Figure 6. Imaginary part of the relative dielectric permittivity plotted versus frequency for four different Anadarko shale samples. Samples are dry and at room temperature and each has a slightly different organic content.

Figure 7. Real part of the relative dielectric permittivity plotted versus frequency for an Anvil points shale sample with different levels of saturation with de-ionized water. Saturation ranges from $0 \%$ (dry, bottom curve) to $86 \%$ (top curve).

Figure 8. Imaginary part of the relative dielectric permittivity plotted versus frequency for an Anvil points shale sample with different levels of saturation with de-ionized water. Saturation ranges from $0 \%$ (dry, bottom curve) to $86 \%$ (top curve). 
Figure 9. Real part of the relative dielectric permittivity plotted versus frequency for a dry Anvil Points shale sample heated to different temperatures. Sample was cored in the direction parallel to layering. Permittivity initially increases with temperature up to 65 ${ }^{\circ} \mathrm{C}$, then decreases as temperature increases to $100{ }^{\circ} \mathrm{C}$.

Figure 10. Imaginary part of the relative dielectric permittivity plotted versus frequency for a dry Anvil Points shale sample heated to different temperatures. Sample was cored in the direction parallel to layering. Permittivity initially increases with temperature up to 65 ${ }^{\circ} \mathrm{C}$, then decreases as temperature increases to $100{ }^{\circ} \mathrm{C}$.

Figure 11. Real part of the dielectric permittivity plotted versus frequency for three different temperatures of dry Anvil Points shale cored in the direction perpendicular to layering. Only a slight increase in permittivity is noted as temperature increases to 146 ${ }^{\circ} \mathrm{C}$. The decrease above $500 \mathrm{MHz}$ for the $146^{\circ} \mathrm{C}$ curves is due to a failure of the fixture compensation at temperature for the higher frequencies.

Figure 12. Imaginary part of the dielectric permittivity plotted versus frequency for three different temperatures of dry Anvil Points shale cored in the direction perpendicular to layering. Only a slight increase in permittivity is noted as temperature increases to 146 ${ }^{\circ} \mathrm{C}$. The decrease above $500 \mathrm{MHz}$ for the $146^{\circ} \mathrm{C}$ curves is due to a failure of the fixture compensation at temperature for the higher frequencies.

Figure 13. Skin depth versus frequency, calculated from relative dielectric permittivity data, of four different dry Anadarko shale samples. Skin depth is relatively large for dry samples because of low loss factor. A smoothing algorithm has been applied to these curves to eliminate noise spikes; see text for explanation.

Figure 14. Skin depth versus frequency, calculated from relative dielectric permittivity data, of four different dry Anvil Points shale samples. Skin depth is relatively large for dry samples because of low loss factor. A smoothing algorithm has been applied to these curves to eliminate noise spikes; see text for explanation.

Figure 15. Skin depth versus frequency, calculated from relative dielectric permittivity data, of four different Anadarko shale samples at different levels of saturation with deionized water. Dry samples have much larger skin depth because of low loss factor; we observed values in the direction perpendicular to layering (labeled "p") to be slightly lower than those of samples cored parallel to layering (labeled " $\mathrm{t}$ ").

Figure 16. Skin depth versus frequency, calculated from relative dielectric permittivity data, of an Anvil Points shale sample with different levels of saturation of de-ionized water. Sample was cored in the direction perpendicular to layering. Skin depth increases greatly as saturation increases. 
Figure 17. Skin depth plotted versus frequency for different brine saturations of an Anadarko shale sample. Note the large difference between the " $\mathrm{t}$ " (parallel to layering) and "p" (perpendicular to layering) measurement directions. 


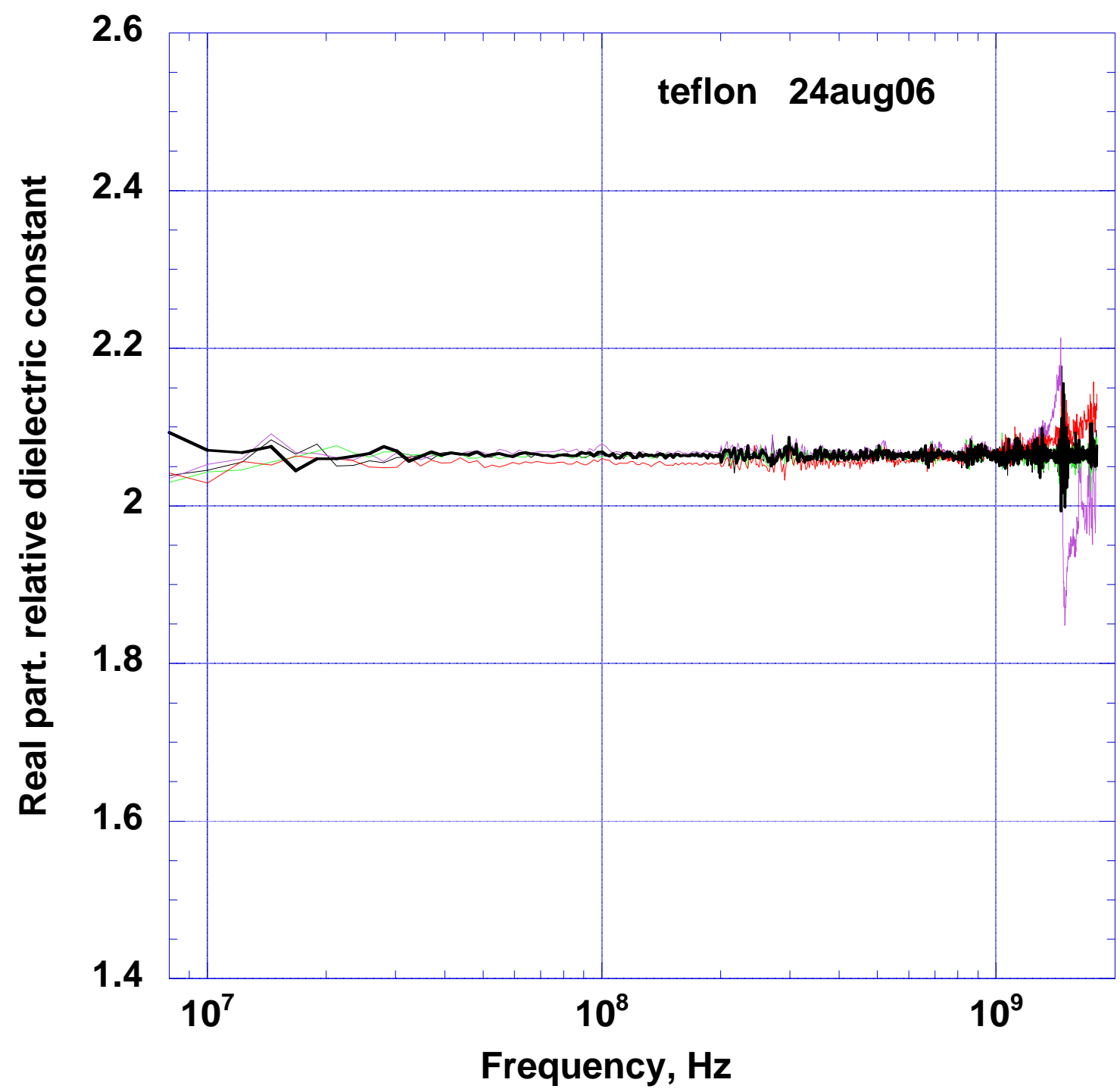

Figure 1. Real part of relative dielectric permittivity measured on a Teflon sample, plotted versus applied frequency. Five separate measurements, with instrument compensation, are shown. 


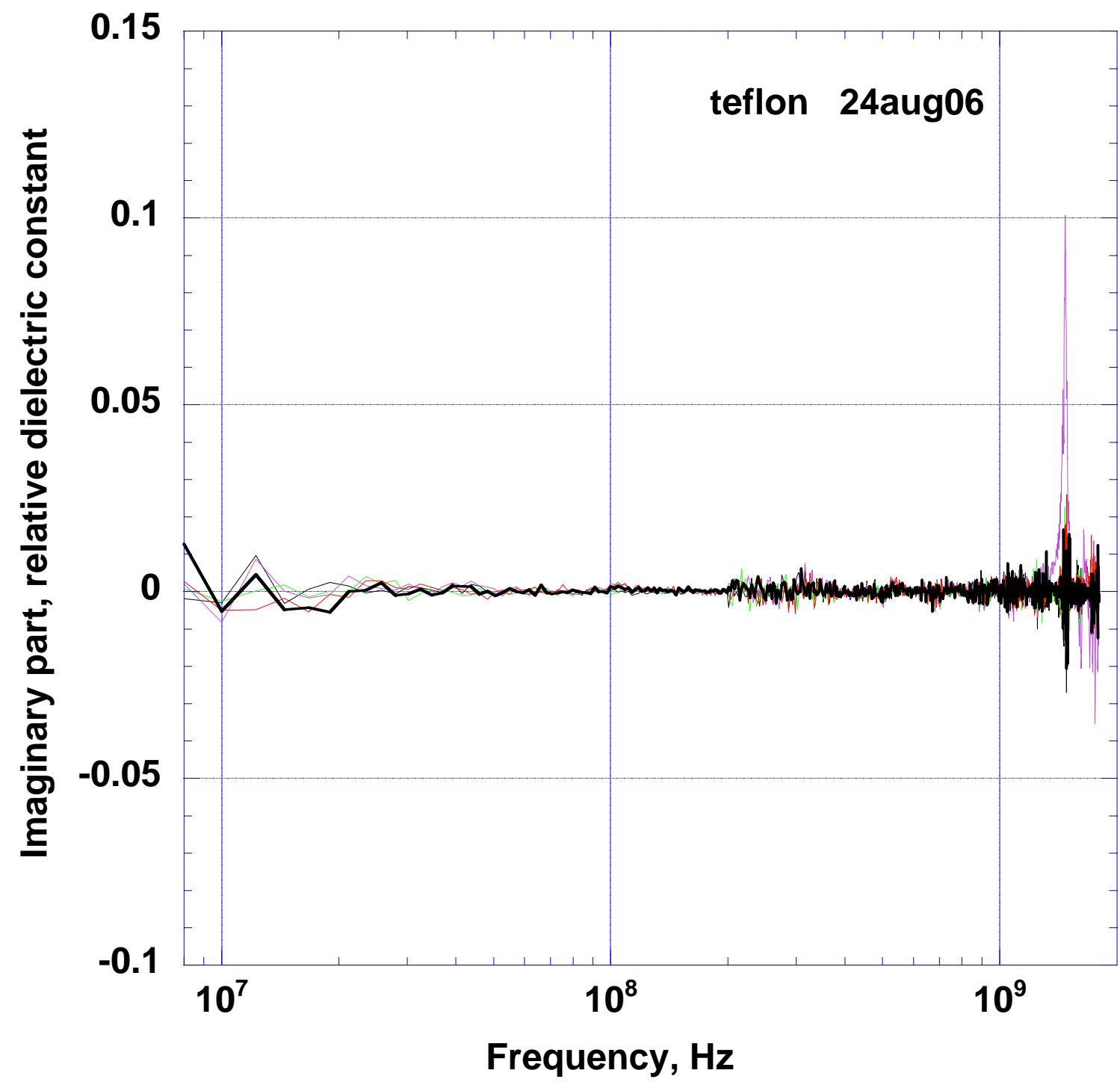

Figure 2. Imaginary part of relative dielectric permittivity measured on a Teflon sample, plotted versus applied frequency. Five separate measurements, with instrument compensation, are shown. 


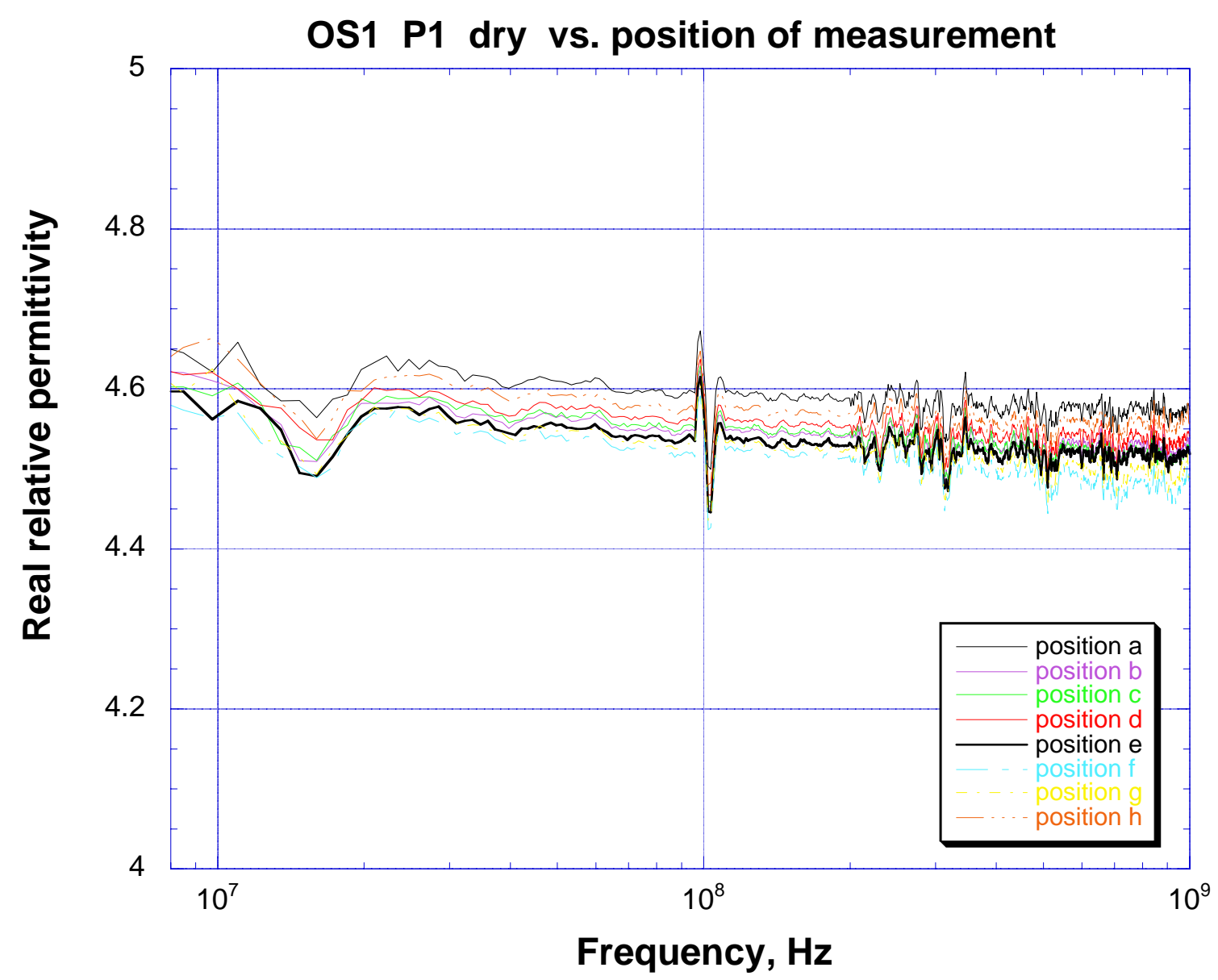

Figure 3. Real part of relative dielectric permittivity plotted versus frequency for a dry Anvil Points shale sample. This sample was cored in the direction perpendicular to layering. Eight separate measurements, made at different points in single sample, are shown. 


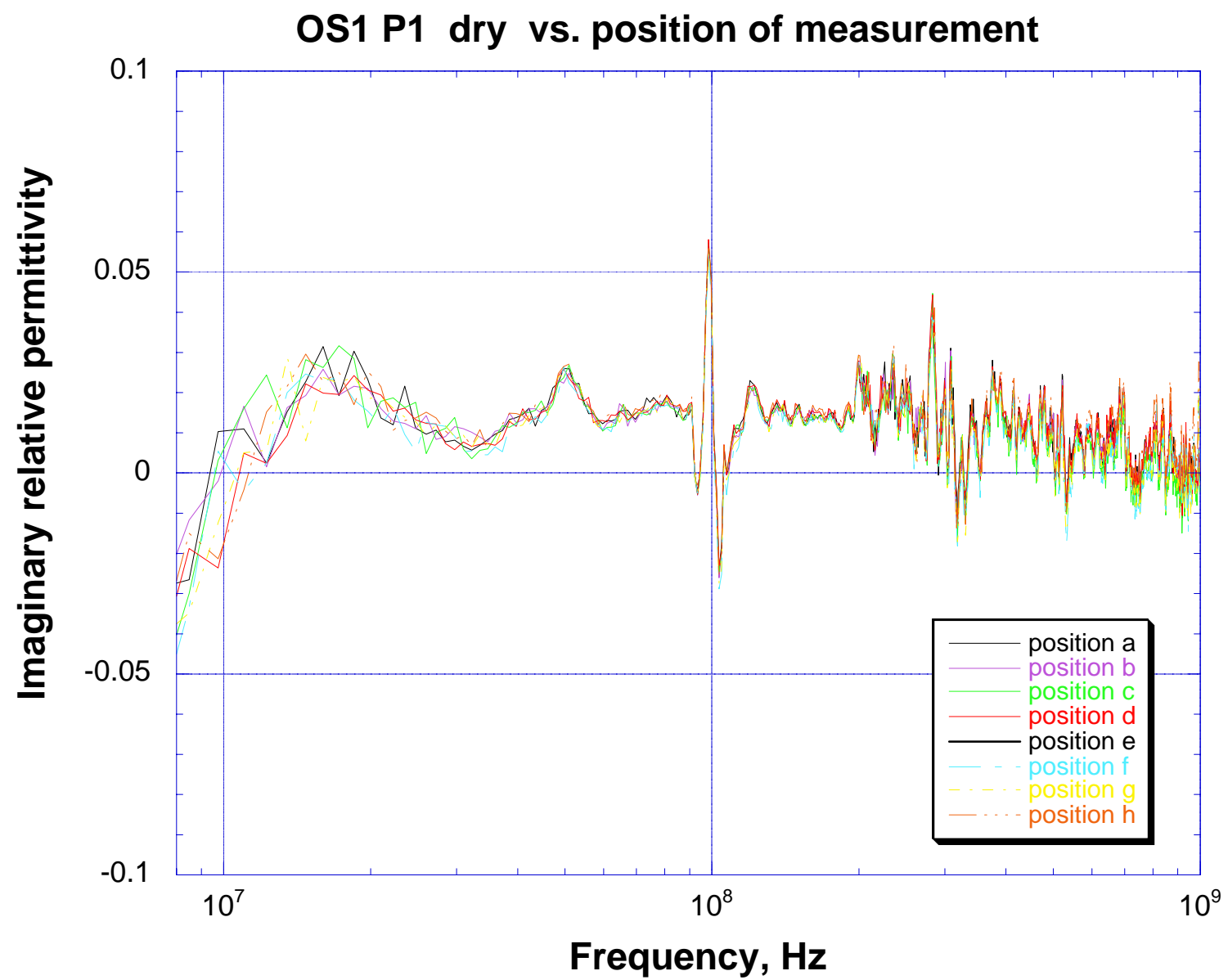

Figure 4. Imaginary part of relative dielectric permittivity plotted versus frequency for a dry Anvil Points shale sample. This sample was cored in the direction perpendicular to layering. Eight separate measurements, made at different points in single sample, are shown. 


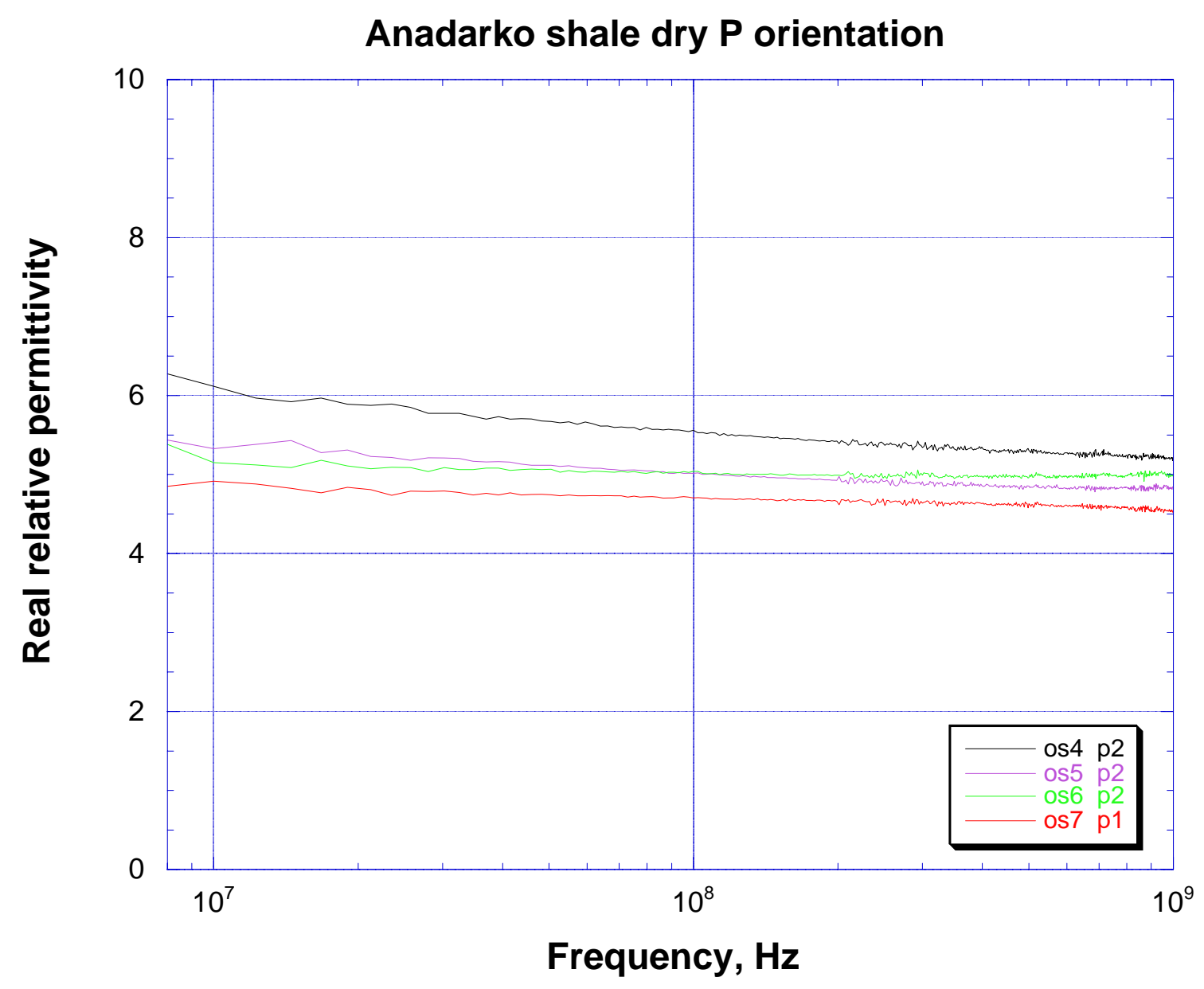

Figure 5. Real part of the relative dielectric permittivity plotted versus frequency for four different Anadarko shale samples. Samples are dry and at room temperature and each has a slightly different organic content. 


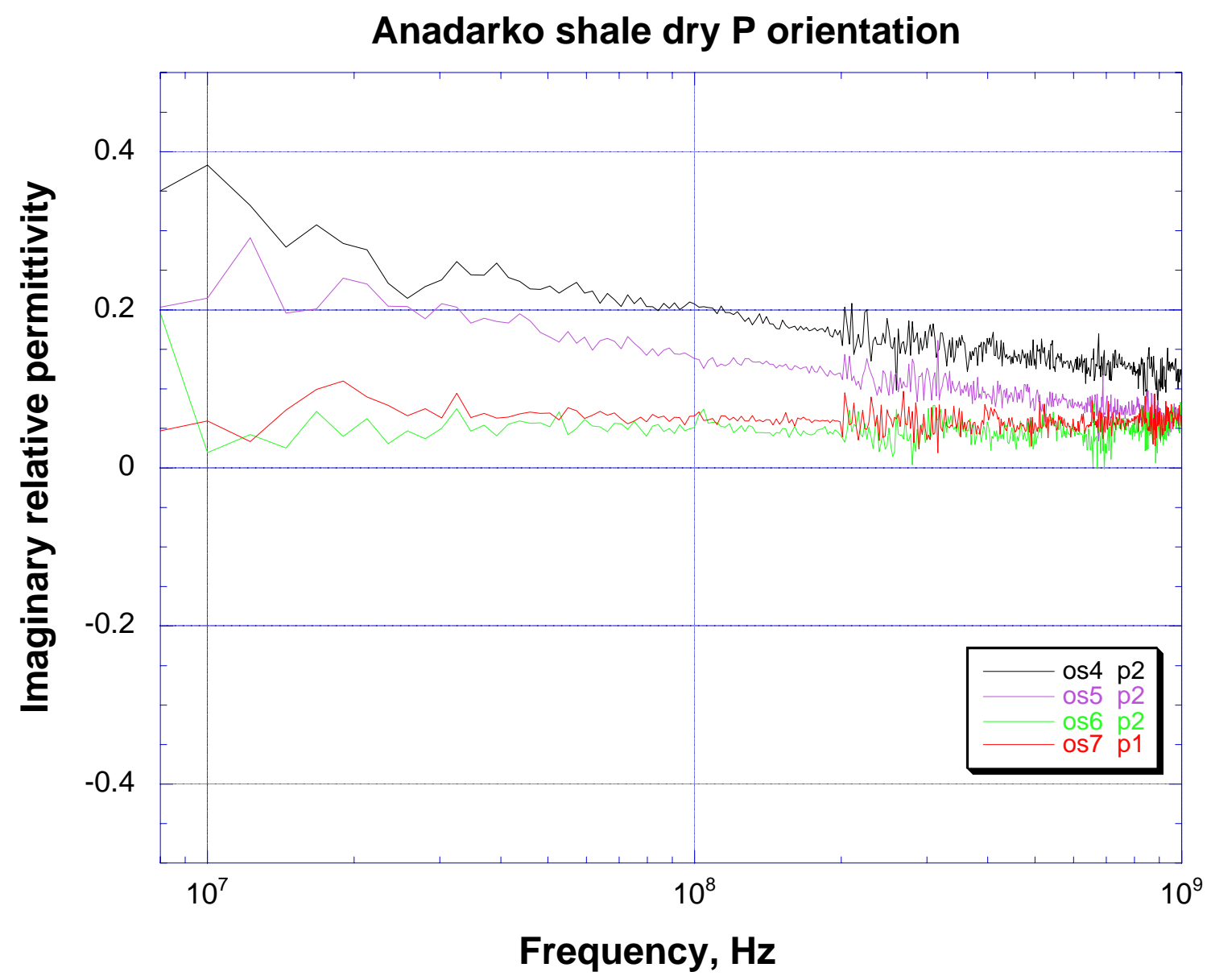

Figure 6. Imaginary part of the relative dielectric permittivity plotted versus frequency for four different Anadarko shale samples. Samples are dry and at room temperature and each has a slightly different organic content. 


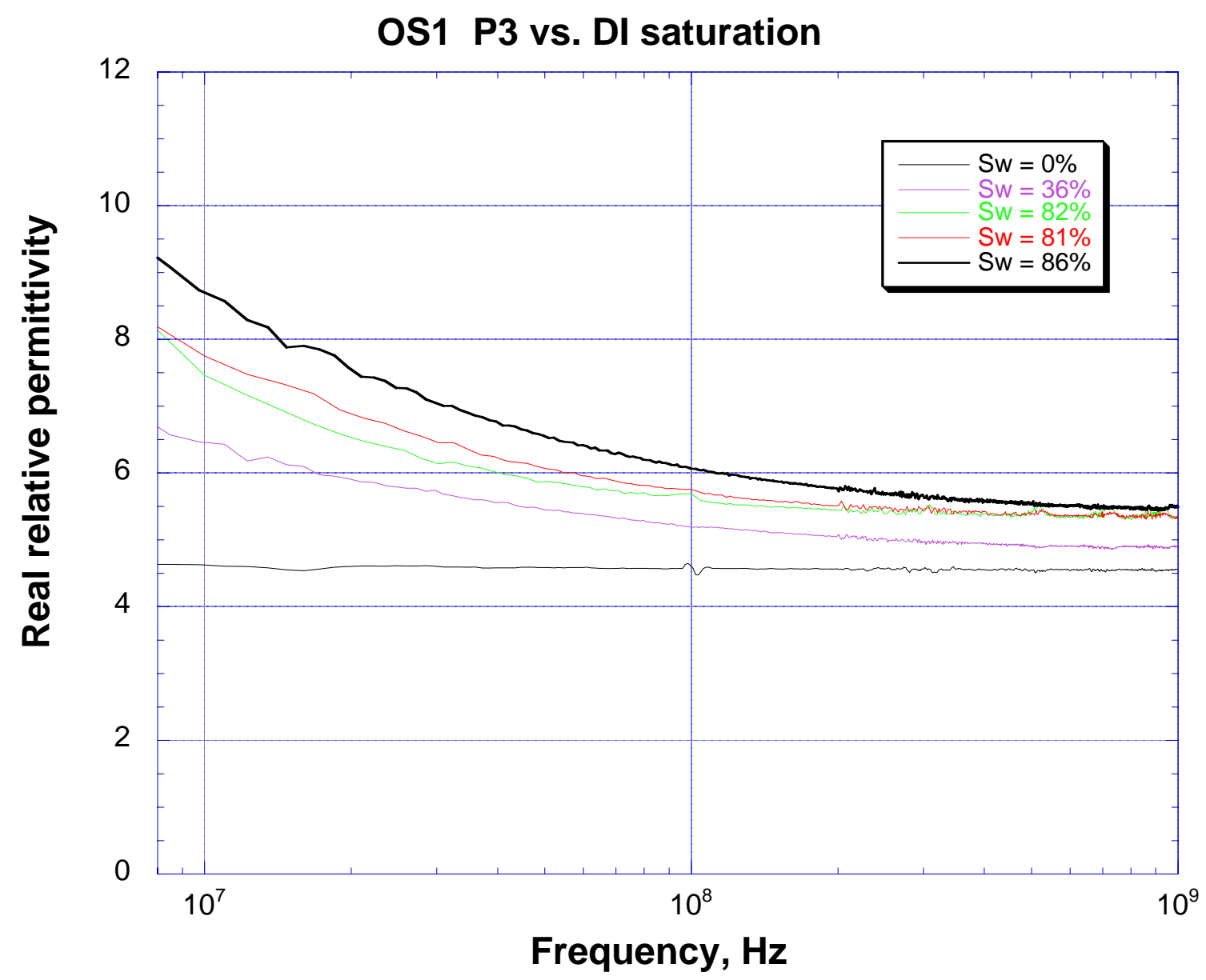

Figure 7. Real part of the relative dielectric permittivity plotted versus frequency for an Anvil points shale sample with different levels of saturation with de-ionized water. Saturation ranges from $0 \%$ (dry, bottom curve) to 86\% (top curve). 


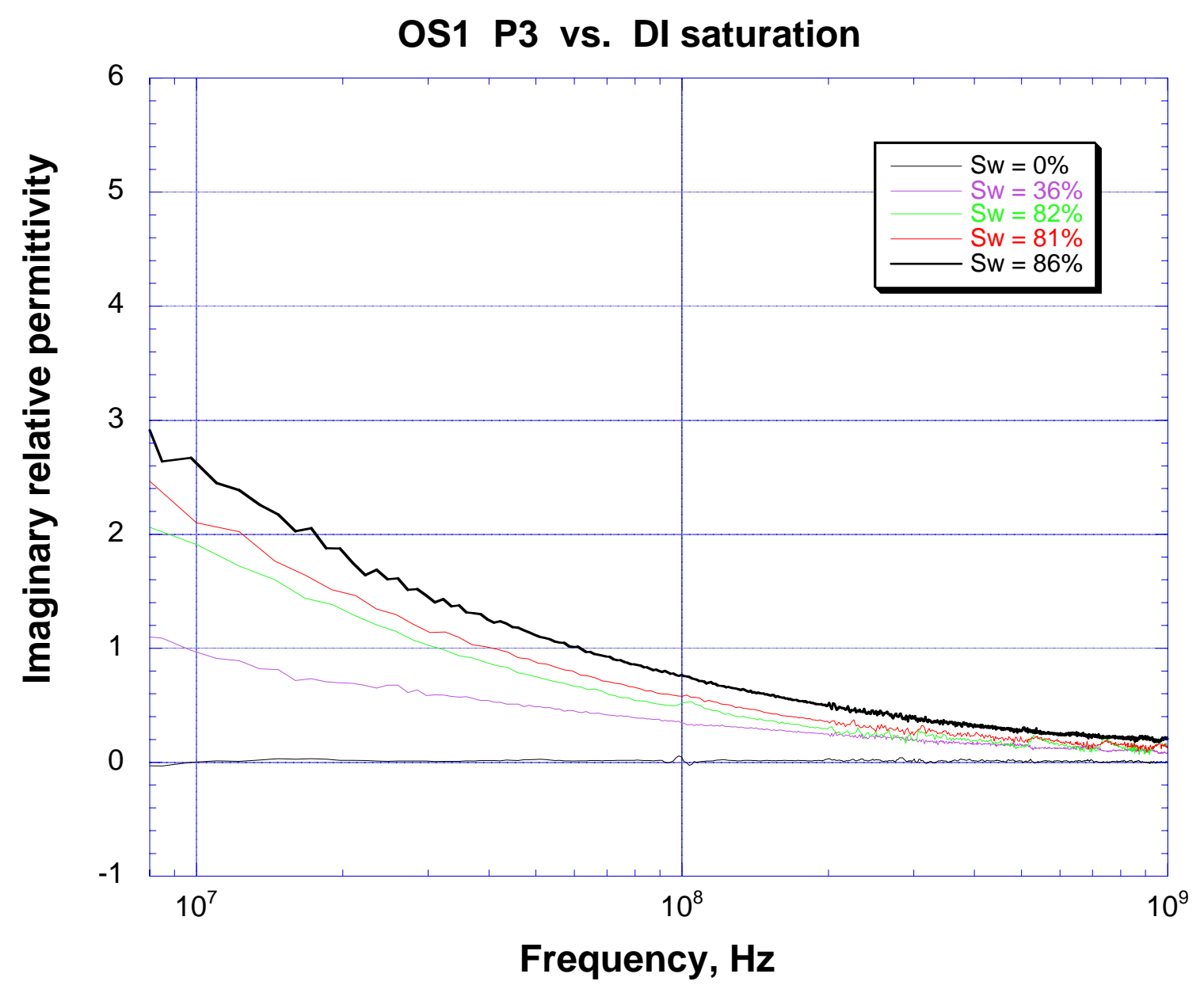

Figure 8. Imaginary part of the relative dielectric permittivity plotted versus frequency for an Anvil points shale sample with different levels of saturation with de-ionized water. Saturation ranges from 0\% (dry, bottom curve) to 86\% (top curve). 


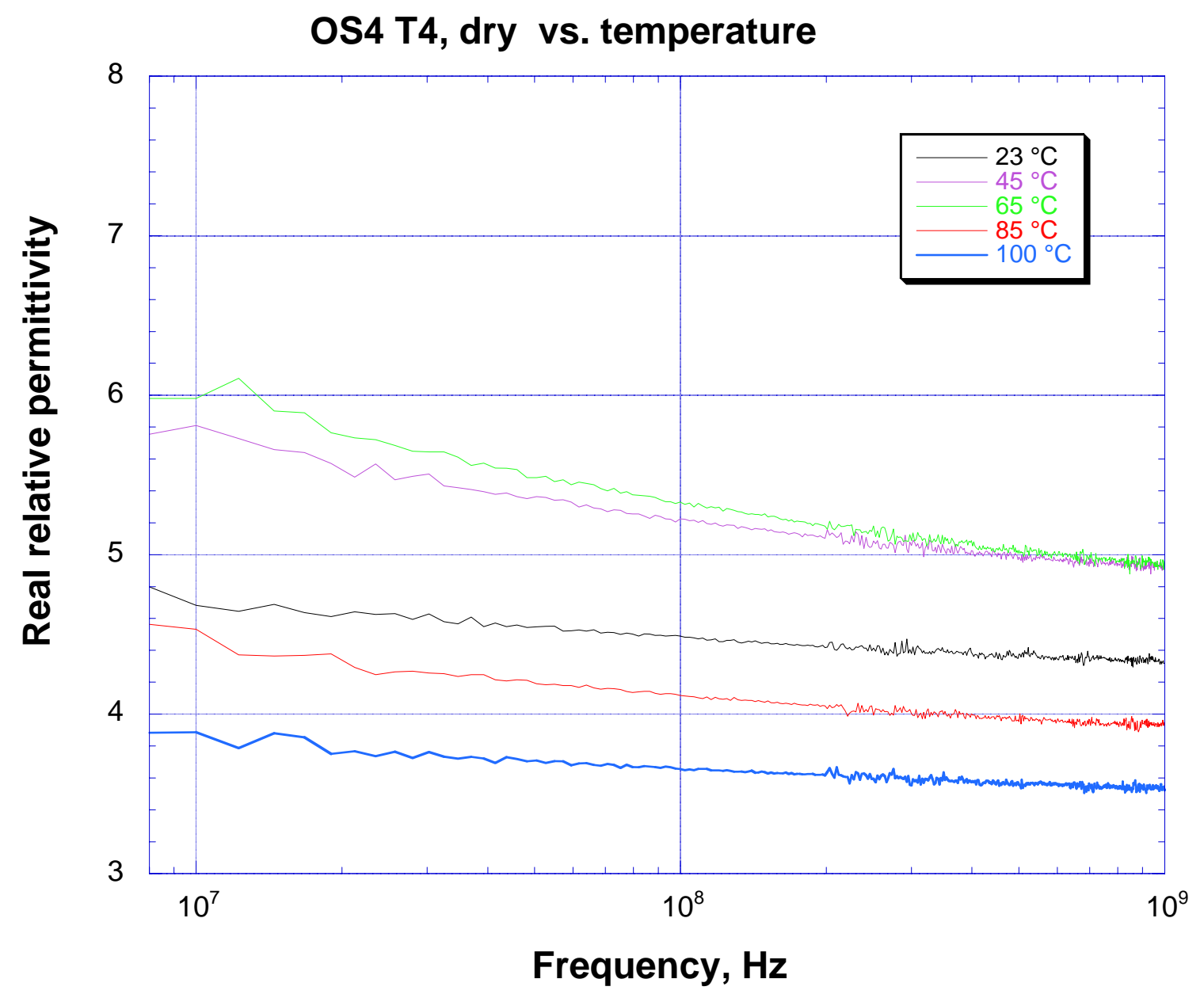

Figure 9. Real part of the relative dielectric permittivity plotted versus frequency for a dry Anvil Points shale sample heated to different temperatures. Sample was cored in the direction parallel to layering. Permittivity initially increases with temperature up to 65 ${ }^{\circ} \mathrm{C}$, then decreases as temperature increases to $100{ }^{\circ} \mathrm{C}$. 


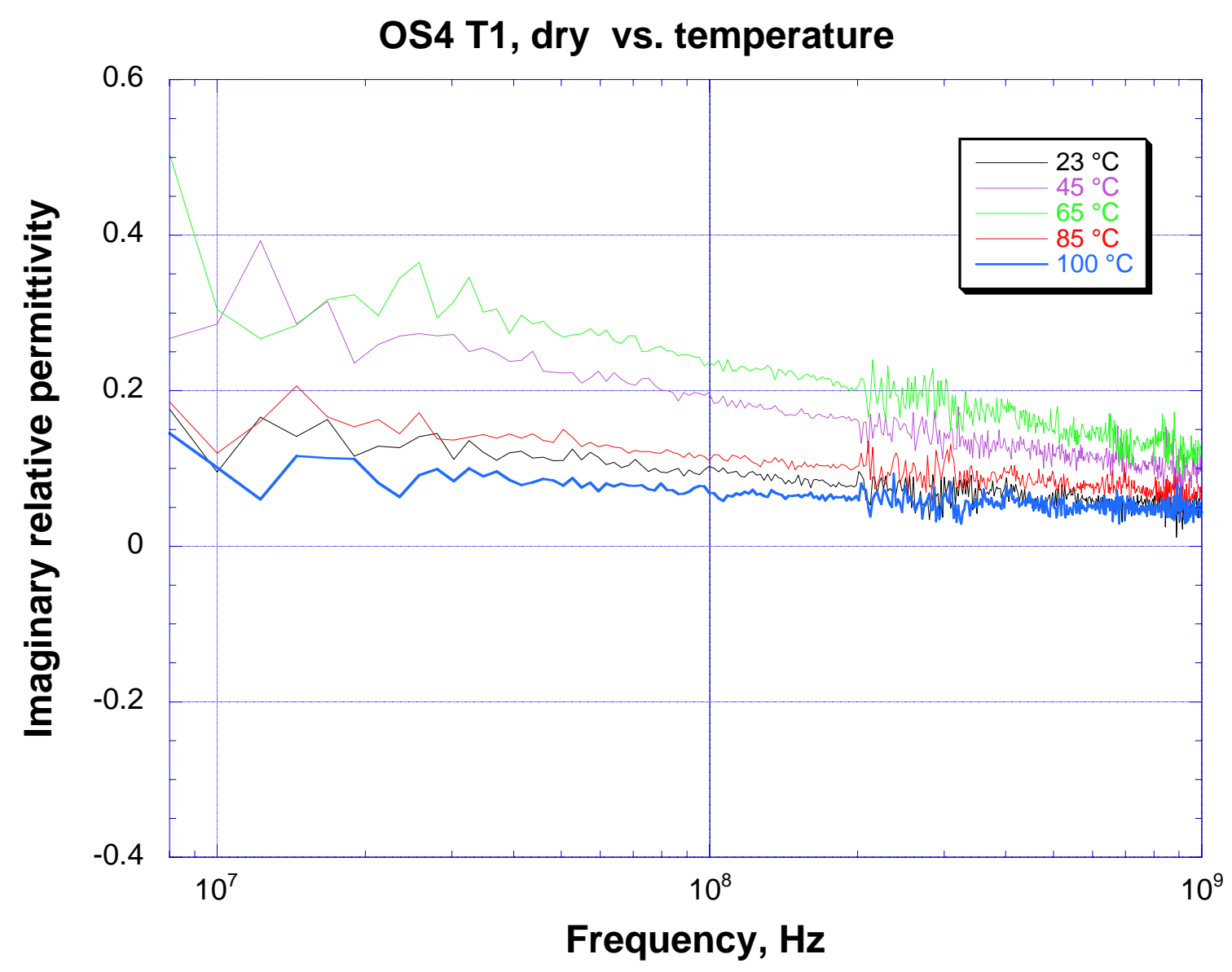

Figure 10. Imaginary part of the relative dielectric permittivity plotted versus frequency for a dry Anvil Points shale sample heated to different temperatures. Sample was cored in the direction parallel to layering. Permittivity initially increases with temperature up to 65 ${ }^{\circ} \mathrm{C}$, then decreases as temperature increases to $100{ }^{\circ} \mathrm{C}$. 


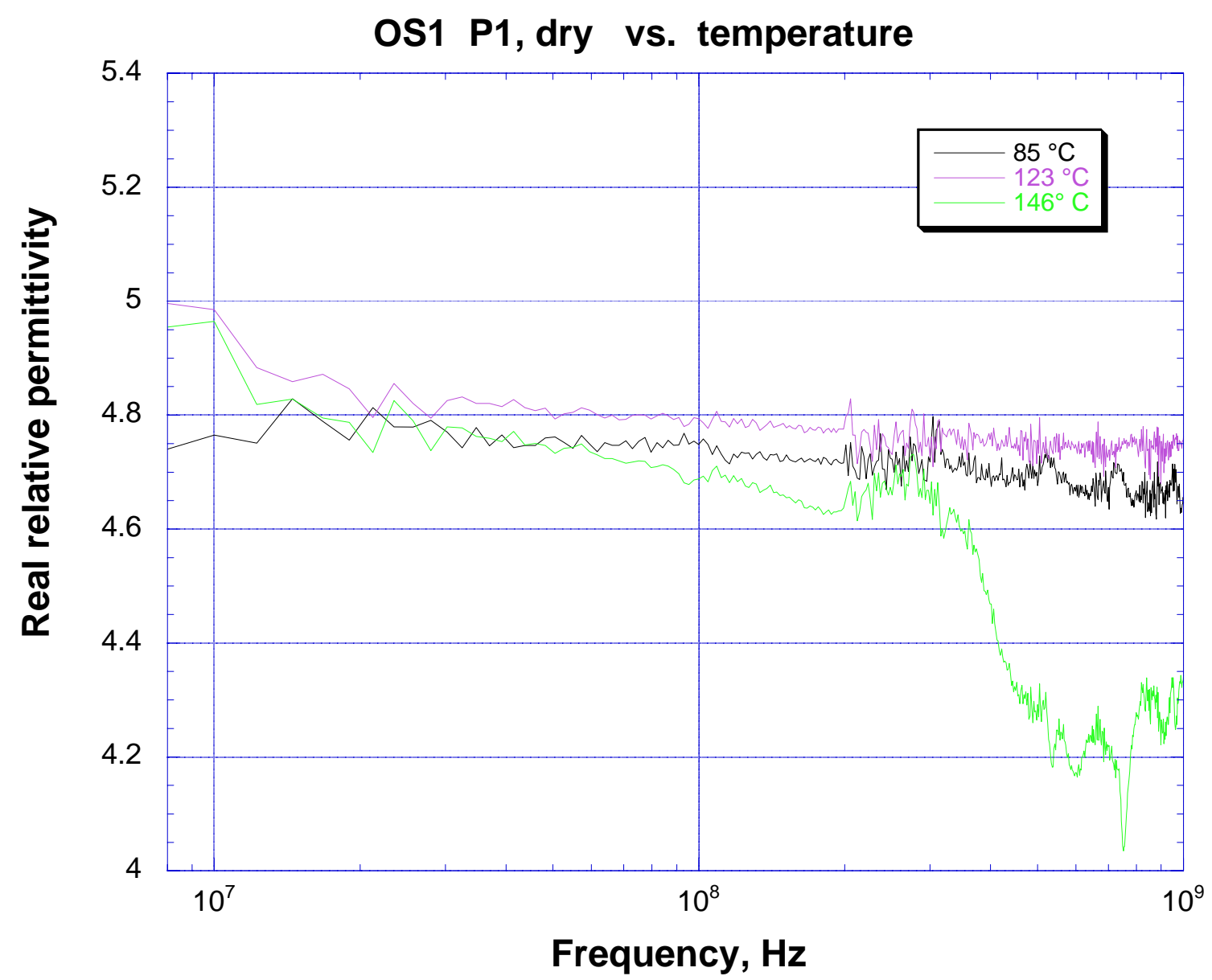

Figure 11. Real part of the dielectric permittivity plotted versus frequency for three different temperatures of dry Anvil Points shale cored in the direction perpendicular to layering. Only a slight increase in permittivity is noted as temperature increases to 146 ${ }^{\circ} \mathrm{C}$. The decrease above $500 \mathrm{MHz}$ for the $146{ }^{\circ} \mathrm{C}$ curves is due to a failure of the fixture compensation at temperature for the higher frequencies. 


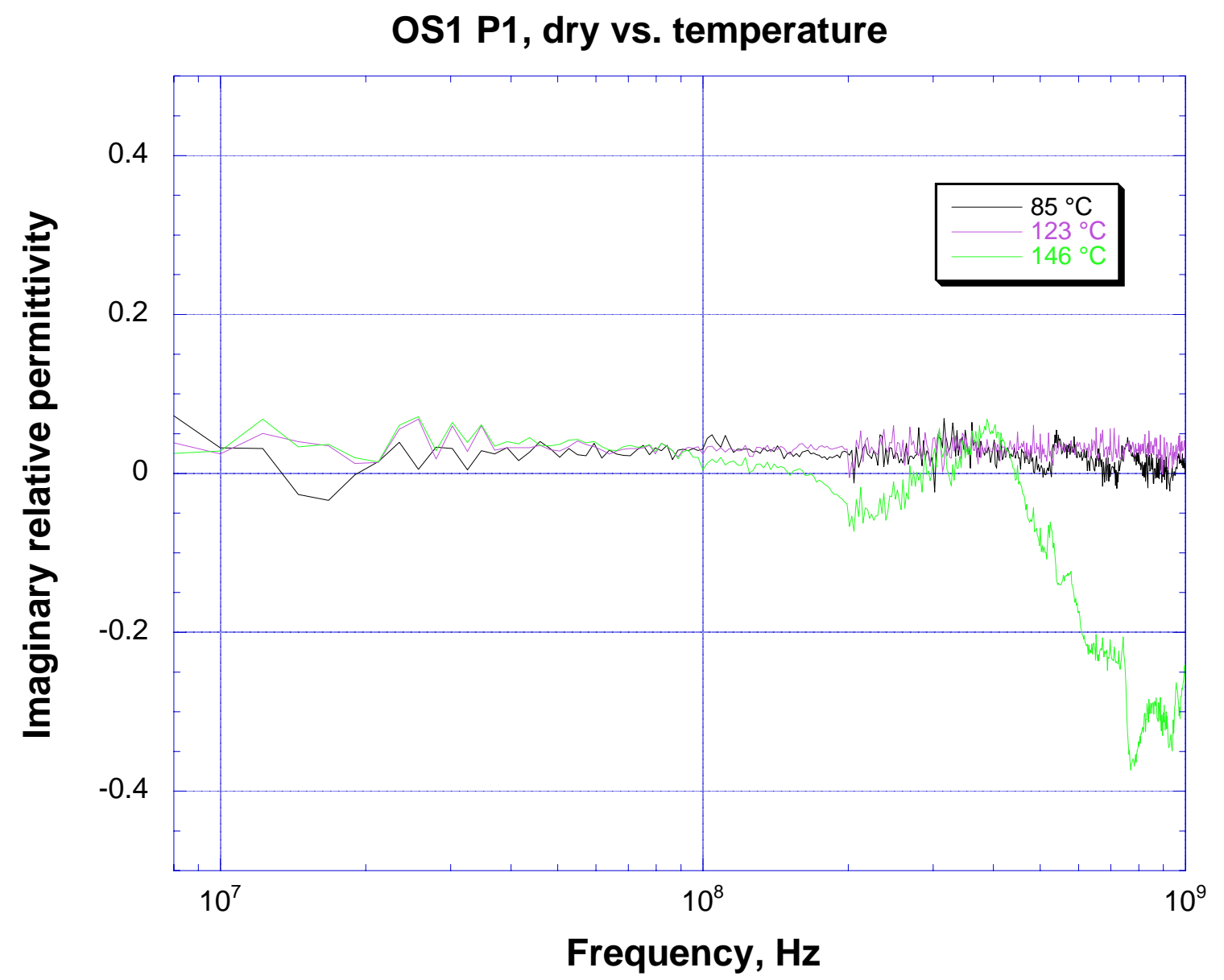

Figure 12. Imaginary part of the dielectric permittivity plotted versus frequency for three different temperatures of dry Anvil Points shale cored in the direction perpendicular to layering. Only a slight increase in permittivity is noted as temperature increases to 146 ${ }^{\circ} \mathrm{C}$. The decrease above $500 \mathrm{MHz}$ for the $146{ }^{\circ} \mathrm{C}$ curves is due to a failure of the fixture compensation at temperature for the higher frequencies. 


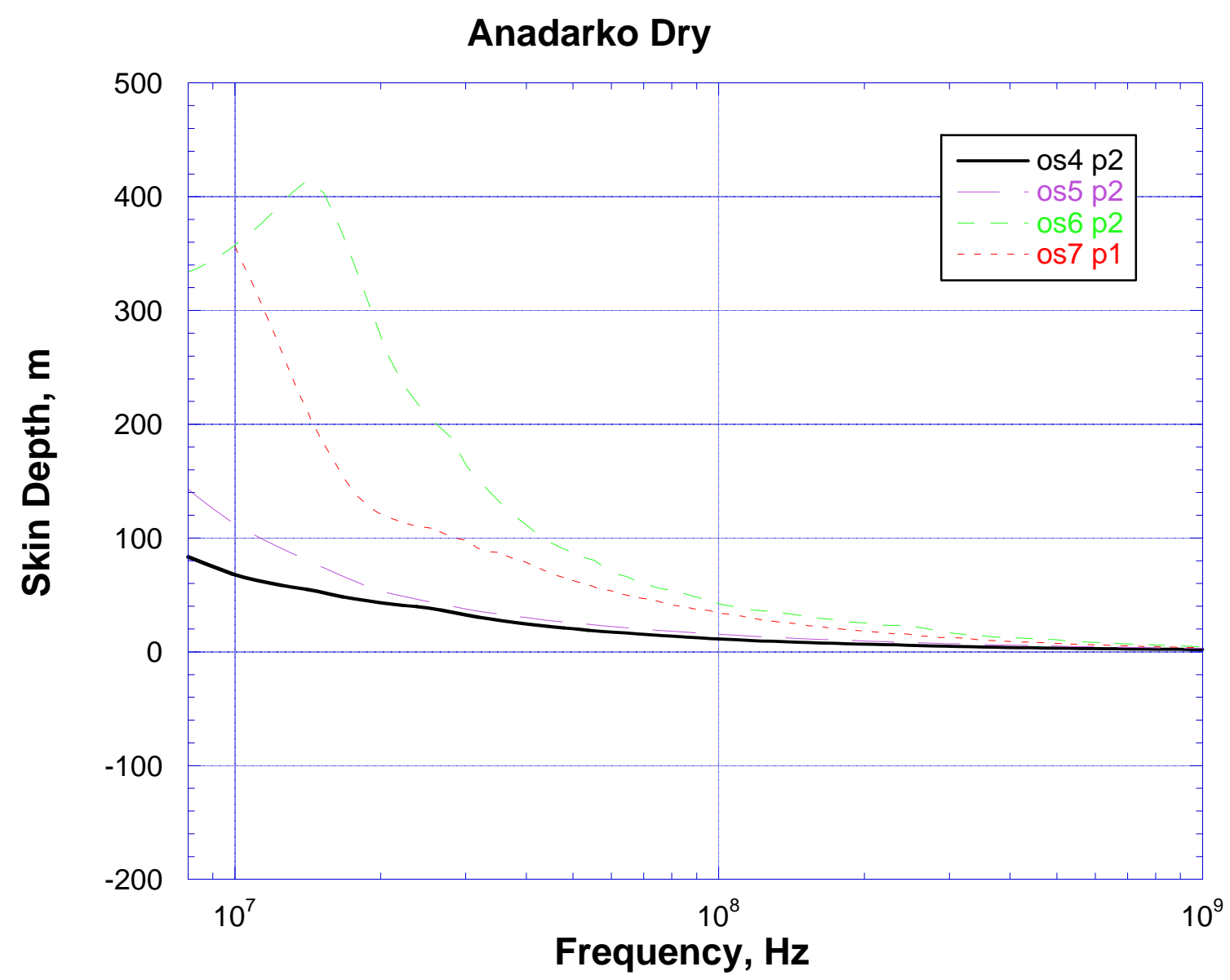

Figure 13. Skin depth versus frequency, calculated from relative dielectric permittivity data, of four different dry Anadarko shale samples. Skin depth is relatively large for dry samples because of low loss factor. A smoothing algorithm has been applied to these curves to eliminate noise spikes; see text for explanation. 


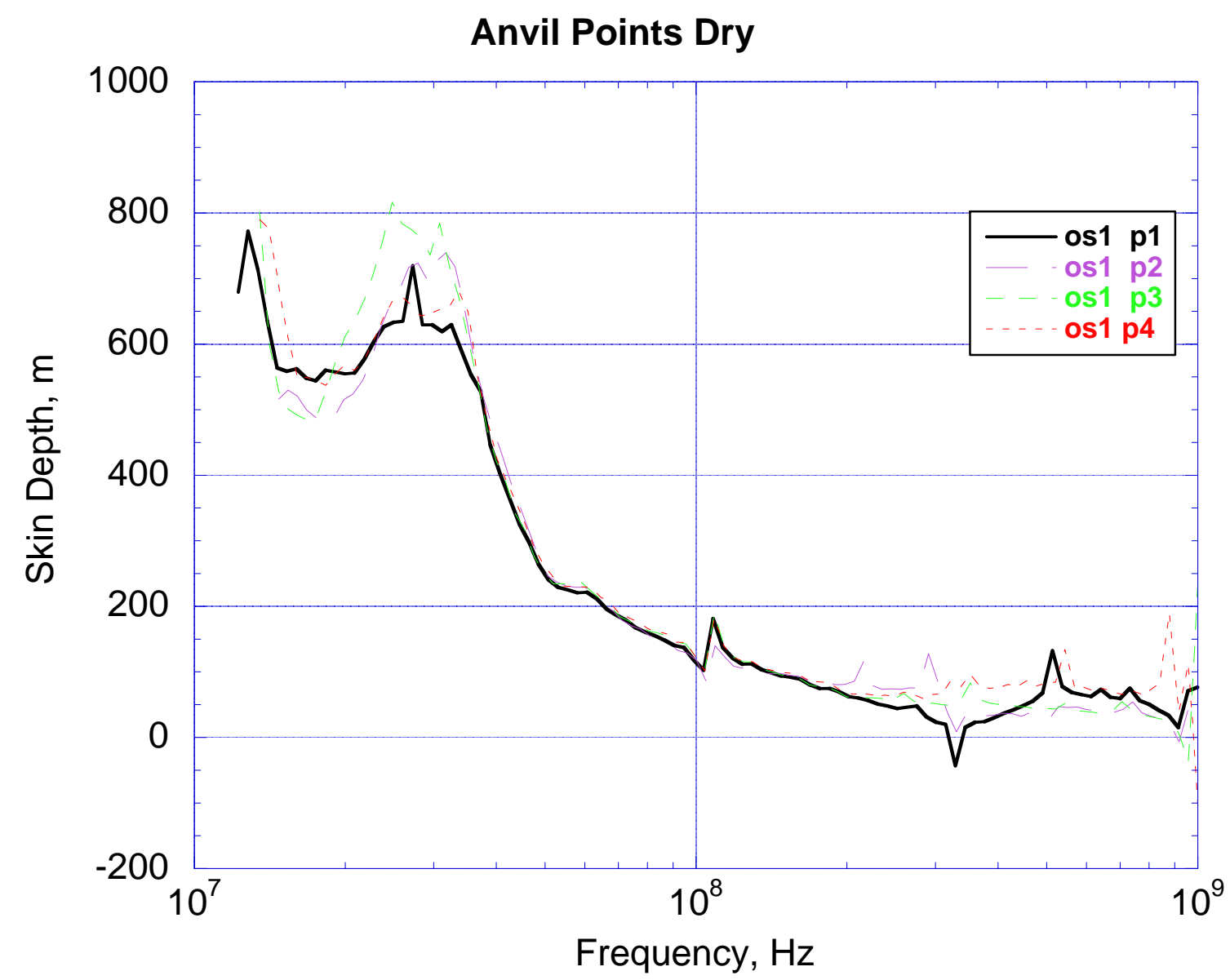

Figure 14. Skin depth versus frequency, calculated from relative dielectric permittivity data, of four different dry Anvil Points shale samples. Skin depth is relatively large for dry samples because of low loss factor. A smoothing algorithm has been applied to these curves to eliminate noise spikes; see text for explanation. 


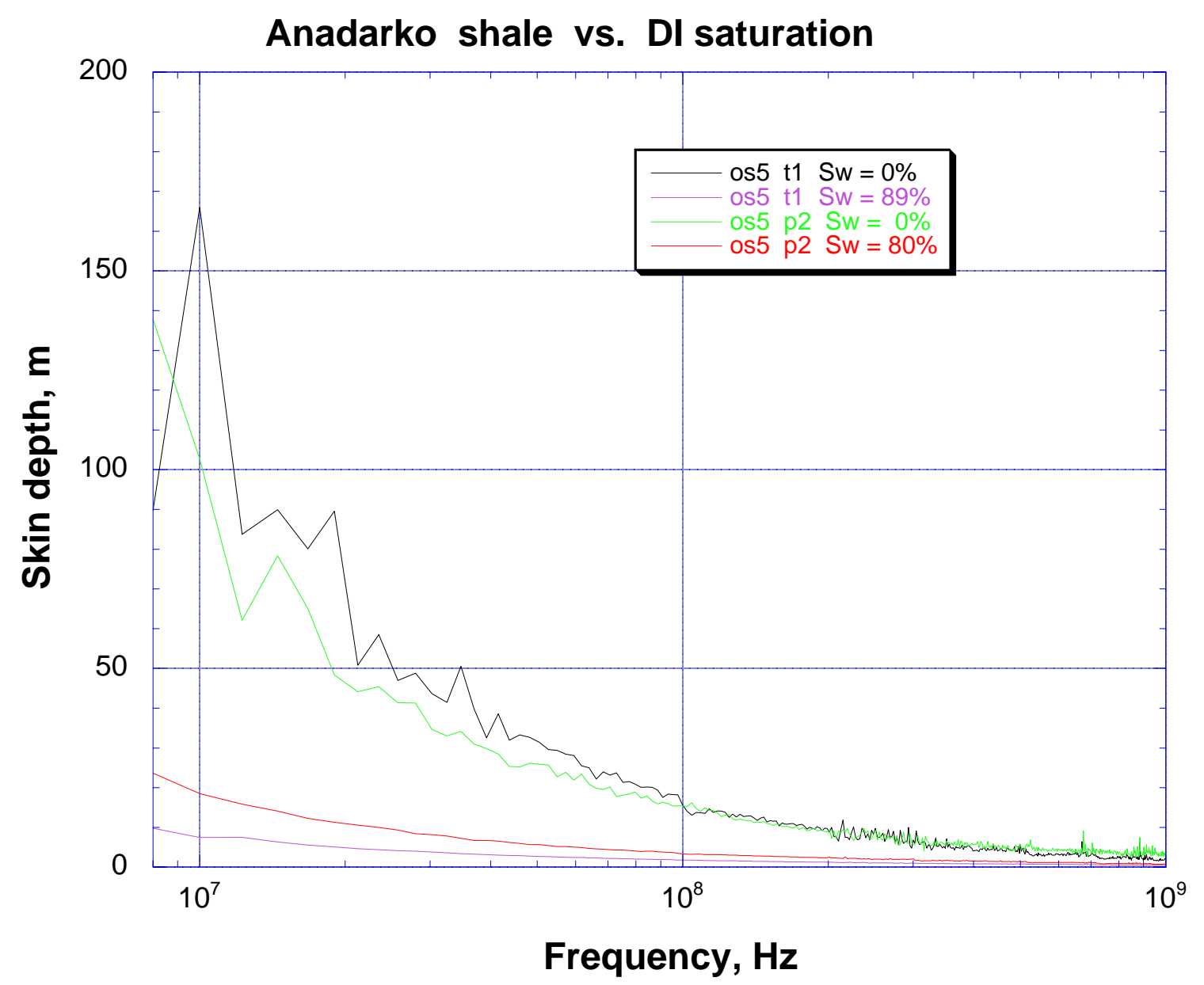

Figure 15. Skin depth versus frequency, calculated from relative dielectric permittivity data, of four different Anadarko shale samples at different levels of saturation with deionized water. Dry samples have much larger skin depth because of low loss factor; we observed values in the direction perpendicular to layering (labeled "p") to be slightly lower than those of samples cored parallel to layering (labeled " $\mathrm{t}$ ”). 


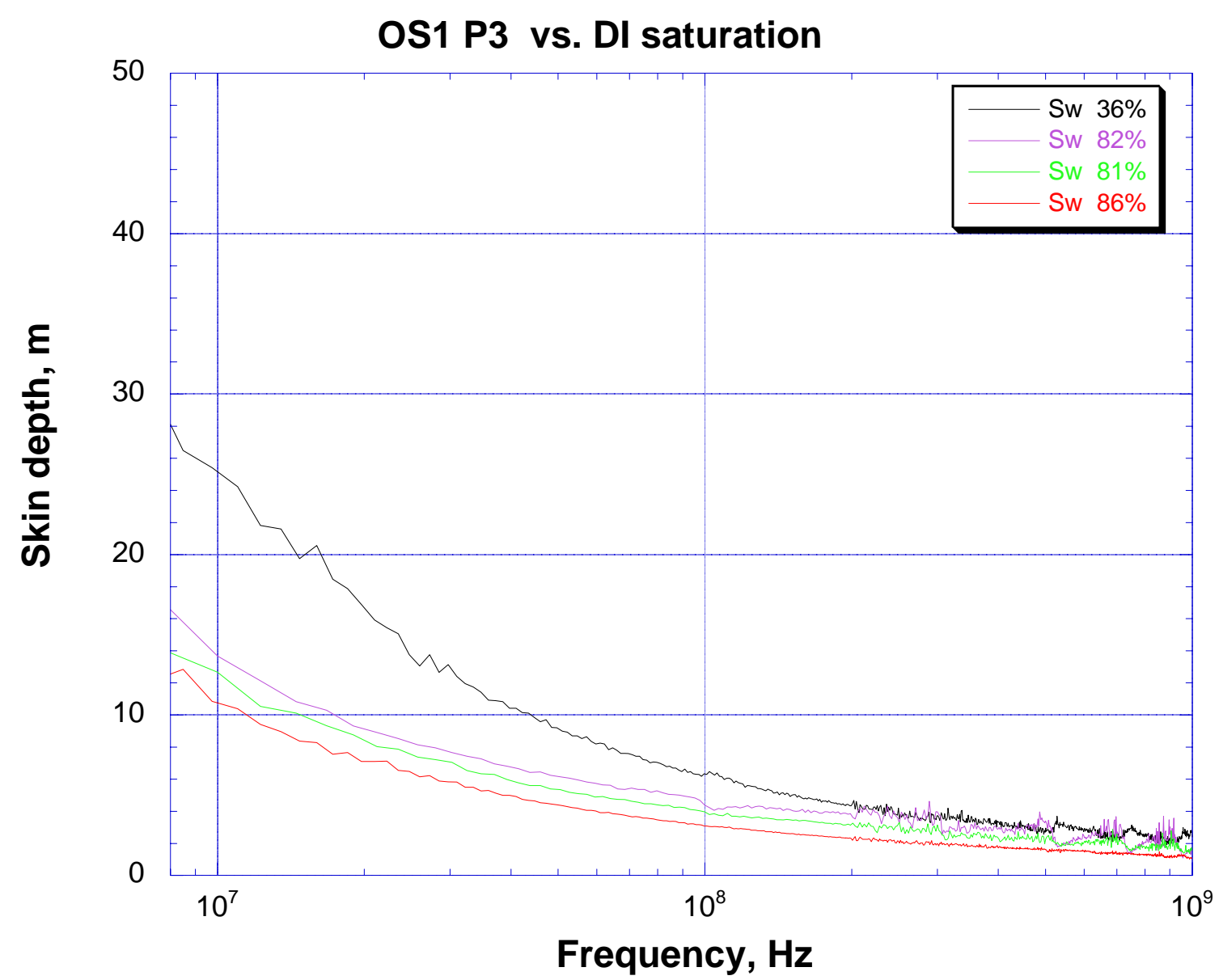

Figure 16. Skin depth versus frequency, calculated from relative dielectric permittivity data, of an Anvil Points shale sample with different levels of saturation of de-ionized water. Sample was cored in the direction perpendicular to layering. Skin depth increases greatly as saturation increases. 


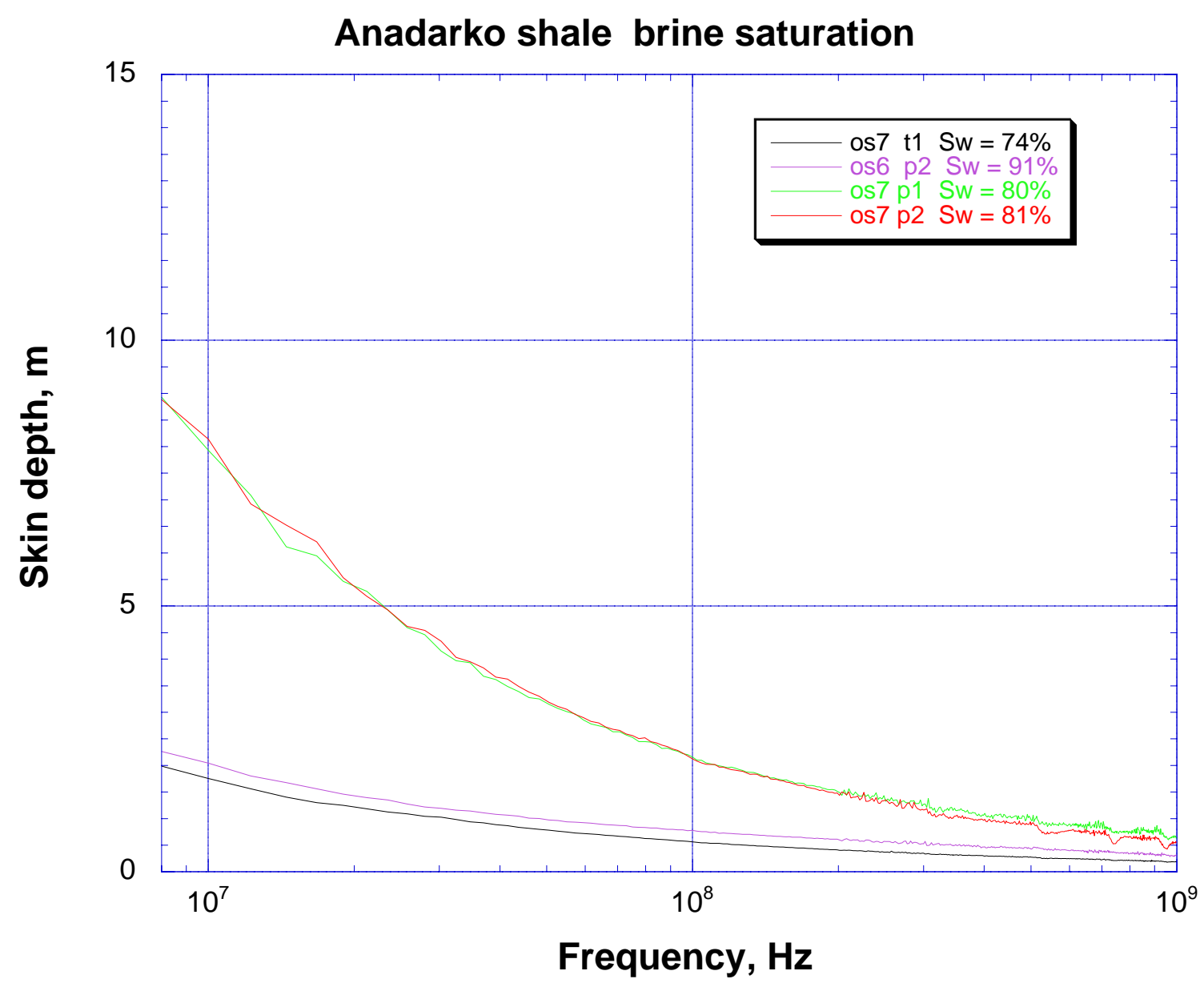

Figure 17. Skin depth plotted versus frequency for different brine saturations of an Anadarko shale sample. Note the large difference between the " $\mathrm{t}$ " (parallel to layering) and "p" (perpendicular to layering) measurement directions. 